\title{
SOBRE A IDENTIDADE NARRATIVA E A IMPUTABILIDADE A PARTIR DE RICOEUR
}

\section{Elton Moreira Quadros ${ }^{1}$}

\begin{abstract}
Resumo
O presente artigo, fruto de uma pesquisa em andamento, problematiza a questão posta por Paul Ricoeur sobre a relação entre identidade narrativa e imputabilidade. Essa discussão proposta pelo filósofo francês nos leva a abordar outras categorias como reconhecimento de si que aborda o percurso realizado pelo homem em direção à identidade, compreendida, não como algo fixo, mas num entendimento da subjetividade como narrativa na duração; homem capaz que caracteriza as capacidade humanas, como o "poder falar", "poder agir" e "poder ser responsabilizado", entre outros; e a dialética memória-promessa que mostra a relação entre o passado/lembrança que está ligado ao papel da testemunha e a promessa que só pode ser cumprida por alguém que é responsável. Neste sentido, visamos compreender como se dá o processo do homem ser capaz de imputar-se e ser imputado em suas ações e, portanto, ser responsável do ponto de vista ético-jurídico. As incertezas, as obscuridades da existência e as próprias vicissitudes, na duração da vida, estão sempre e de novo em busca de uma configuração narrativa. No âmbito da intimidade da subjetividade, quando colocamos em movimento a identidade narrativa já estamos no espaço de uma discussão pública.
\end{abstract}

Palavras-chave: ética; memória; reconhecimento; responsabilidade; subjetividade

\section{CONSIDERAÇÕES INICIAIS}

$\mathrm{Na}$ obra de Ricoeur, especialmente no longo percurso que vai de Tempo e narrativa até chegar em Memória, história, esquecimento, encontraremos uma discussão gradual e com algumas bifurcações hermenêuticas em que a questão da identidade fica posta e confrontada. Quando pensamos em identidade, corremos o risco de ter uma noção desse termo que seja dada de modo imediato, sem matizes, de maneira fixa e excludente do outro, da alteridade e mesmo da mudança. Essa perspectiva acaba por confundir aquilo que é o idem, ou na linguagem ricoeuriana, a Mesmidade com o que está naquilo que é mais propriamente humano, ou seja, a Ipseidade (ipse), essa é a realidade efetiva da compreensão de um próprio que nos possibilita um caminho de identidade dentro da própria narrativa existencial, dentro da relação com o outroe com o mundo.

\footnotetext{
${ }^{1}$ Doutor em Memória: Linguagem e Sociedade na Universidade Estadual do Sudoeste da Bahia (UESB). Professor do Departamento de Educação - DEDC, no Colegiado do Curso de Direito, da Universidade do Estado da Bahia (UNEB). Professor do quadro permanente do PPG em Ecologia Humana e Gestão Socioambiental da Universidade do Estado da Bahia (UNEB). Líder do Grupo de Pesquisa em Fenomenologia, Memória e Justiça. E-mail: eltonquadros@yahoo.com.br
} 
Temos assim, a Ipseidade, entendida como aquilo que singulariza a pessoa, quer na questão da linguagem, da ação, da narrativa e da relação com o mundo e, por outro lado, a Mesmidade que nos coloca em referência aquilo que os outros nos posicionam, quer em relação ao modo como sou referido ou de quais lugares ocupo, mas que ao mesmo tempo não são necessariamente aquilo que me constitui num processo de reconhecimento. Será nesse âmbito que poderemos pensar sobre uma identidade pessoal entendida como uma identidade narrativa, a qual está sempre lançada dentro dessa dialética Ipseidade e Mesmidade.

Por isso, quando nos colocamos a pensar sobre o percurso do reconhecimento, da identidade pessoal, no pensamento de Ricoeur, nos parece fundamental destacar a relação entre o percurso e a memória. Nessa perspectiva, a identidade não constitui um fim, um determinar definitivo sobre o que sou "absolutizado". Para Ricoeur, o homem é definido como um ser capaz (homem capaz):

[...] capaz de se dizer, capaz de fazer, capaz de se responsabilizar, capaz de contar e de se contar, capaz de se lembrar, refazendo laços e dando novos sentidos ao factum, até mesmo ao irreparável e ao injustificável. Por isso, o uso crítico da memória tanto nos impede de ficar amnésicos, como nos liberta da opressão de um passado "congelado", que obsidie a memória com uma fatalidade irreversível. Usar criticamente a memória é, por conseguinte, dizer "não" aos "abusos da memória", exigindo trazer para o centro a categoria da relação que outorga unidade narrativa e diferenciada a uma vida, processo que, num mesmo movimento, não esquece o passado, mas recusa ficar dele cativo. Permanecer entre e em relação: é isto que permite o "trabalho de memória" [...] (ROSA, 2006, p. 2-3).

Ao propormos essa discussão, temos em vista compreender o processo que nos possibilita estabelecer como se dá a responsabilidade sobre uma ação e, consequentemente, a viabilidade da determinação da imputação de um ato a alguém. Acreditamos que esse percurso só pode ser refletido tendo em vista uma análise da subjetividade e da alteridade, isto é, na relação entre o si mesmoe o outro podemos responder às perguntas "quem é responsável por uma ação?", "quem é o autor de um determinado delito?".

O âmbito da subjetividade, entendida como uma identidade narrativa, pode nos propiciar uma perspectiva de análise que dê conta de perceber a imputabilidade como um caminho rico para a aferição da responsabilidade. Com isso, pensamos estabelecer, ao utilizarmos as categorias ricoeurianas, a evidenciação da relação entre ética e filosofia do direito, perspectivas que nem sempre são apresentadas em consonância.

Assim, a atualidade dessa discussão passa por nova maneira de pensar a responsabilidade e a imputabilidade, sem dar somente ênfase naquilo que pode ser considerado somente como um ato individual ou como uma responsabilidade coletiva. Ao fazermos referência ao pensamento de Ricoeur, pretendemos expor as diversas dimensões dessa problemática que tende a ser sempre passar pela pessoa, pelo individuo, mas também, sem nunca perder de vista que o outro e mesmo os outros, são fundamentais para a constituição da identidade de cada um. Sendo assim, é nessa relação dialética que encontramos um caminho para refletir sobre o que é ser responsável e responsabilizável. 
Acreditamos que compreender isso, nos possibilita captar o processo que vai desde o percurso do reconhecimento até a imputabilidade, da identidade narrativa até a responsabilidade, com toda a problemática aí existente.

Vamos refletir agora sobre essas questões (reconhecimento, homem capaz, memória-promessa) e seus entrelaçamentos tendo em vista que esses temas podem nos conduzir para o pensamento que reflete sobre o sujeito de direito (e deveres) e, por consequência, na necessária constituição dos Direitos.

\section{RECONHECIMENTO E HOMEM CAPAZ}

O tema do reconhecimento esteve sempre presente, desde os gregos até os modernos, no entanto, com o passar do tempo vimos desenvolver a compreensão de que há uma "consciência reflexiva de si mesmo implicada" (RICOEUR, 2006, p. 105) no reconhecimento. Ricoeur propõe em oposição aos vocabulários selfou selfhood do inglês, o uso de si mesmo reflexivo e isso constituiria a ipseidade. A perspectiva de Ricoeur visa a desenvolver uma hermenêutica do si a partir da "consideração das capacidades que encontram expressão na forma modal do 'eu posso', desvio pelo objetal para conferir valor reflexivo ao si mesmo" (RICOEUR, 2006, p. 109). Por isso, nos depararemos, nesse processo de compreensão do si, com o homem capaz.

Essa figura conceitual ricoeriana, nos leva à filosofia da ação. Isso nos parece algo muito significativo, uma vez que a expressão "eu posso", que é tão cara a Ricoeur, indica um sujeito, uma pessoa capaz de agir e que só é capaz de realizar uma ação efetiva, aquele que possui o reconhecimento de si. Por outro lado, também é significativo que ser capaz é uma forma de ser efetivo no mundo, uma interioridade que desafia o tempo, como veremos mais abaixo ao falarmos da dialética memória-promessa.

Ao propor uma filosofia do reconhecimento, Ricoeur defende que há um longo trajeto nesse processo:

No trajeto aberto pelo ato soberano do reconhecimento/identificação, [...] o reconhecimento de si, em virtude dessa última dialética [identidade e alteridade], abre também o caminho para a problemática do ser reconhecido, implicado pela exigência de reconhecimento mútuo [...]. Nesse sentido, o reconhecimento de si mesmo ocupa um lugar mediano nesse longo trajeto em razão precisamente dos traços de alteridade que, no âmago da auto-designação do sujeito das capacidades que indica a gramática do "eu posso", se associam aos outros dois traços [...]: a caracterização da ação pelas capacidades em que elas constituem o efetuar-se, e o desvio da reflexão pelo lado objetal das experiências consideradas (RICOEUR, 2006, p. 109).

Assim, podemos perceber que o reconhecimento de si não é um dado fora ou destacado do ser si, mas um dos momentos dessa longa trajetória que leva de um processo em que são identificadas as capacidades de ser e agir do homem definido como capaz, bem como, de um percurso que envolve uma reflexão de si mesmo dentro do processo das próprias experiências, mas nada disso nos fará realmente caminhar pela senda do reconhecimento se, dentro disso, não houver uma confrontação entre a identidade e a alteridade. 
Mas, esse homem capaz é capaz de quê mesmo? Para Ricoeur, o "eu posso" implica em poder dizer, poder fazer, poder narrar e narrar-se, em poder ser responsável (ou responsabilizado) e, também poder lembrar. Em Memória, história e esquecimento, ele deixa claro que "as potencialidades mnemônicas são da mesma ordem [...]. O eu posso me lembrar se inscreve também no registro dos poder fazer do homem capaz" (RICOEUR, 2010, p. 403).

Ricoeur utiliza a definição segundo a qual poder dizer é, em alguma medida, "fazer coisas com as palavras", isto é, "ao inaugurar a ideia de capacidade pelo poder dizer, conferimos de saída à noção de agir humano a extensão que justifica a caracterização como homem capaz do si que se reconhece em suas capacidades" (RICOEUR, 2006, p. 110).

Outro ponto importante de se notar está na questão de que o "poder dizer" indicar também a capacidade de reflexão, que levará a uma outra possibilidade, ou seja, a de poder afirmar algo no e através do dizer. O poder dizer que estaria associado a um ato somente, nos leva, invariavelmente a um "quem", a um quem fala? Quem afirma algo ao dizer? E assim, a utilização dos pronomes pessoais, dos advérbios de tempo e lugar que vão conduzindo a fala a uma autodesignação daquele que fala. Ao dizer "eu", utilizo uma expressão autorreferencial na qual estou implicado.

Essa autodesignação ganha em complexidade, na medida que, normalmente, quem diz, diz em uma situação de interlocução, associando, portanto, reflexividade e alteridade: "a palavra pronunciada por uma pessoa é uma palavra dirigida a outra; além disso, pode ocorrer de ela responder a uma interpelação vinda de outrem" (RICOEUR, 2006, p. 111). A relação discursiva entre locutor e interlocutor encontra na estrutura perguntaresposta a sua forma básica.

Além disso, na relação entre identidade e alteridade, dada na reflexão do poder dizer, chegamos à enunciação de um nome próprio que digo "eu sou..." e, nesse ponto, Ricoeur compreende que o dizer pode instaurar, através da autodesignação do nome próprio, digamos assim, uma fundação do eu:

A autodesignação recebe da denominação muito mais que um aumento de força ilocutório (sic), recebe também um papel de fundação, no sentido em que a atribuição de um nome próprio, segundo as regras convencionais que regem a distribuição dos sobrenomes e dos nomes em uma cultura dada, constitui uma verdadeira instauração concernente a um sujeito falante capaz de dizer "eu, fulano de tal, me chamo Paul Ricoeur" (RICOEUR, 2006, p. 111).

Se o poder dizer leva-nos à dialética entre reconhecimento de si e alteridade, o "posso fazer" põe o sujeito agente num processo de reconhecimento de si como causa de algo, como causa de um acontecimento, a declaração "fui eu que fiz" está na origem mesma da capacidade de afirmação do sujeito, da afirmação de um eu.

Existe, quando falamos de um "fazer ocorrer" e de um "ocorrer", duas distinções que precisamos ter claras: a primeira delas está em perceber que, a cada ação, a cada acontecimento, há uma causa, que é aquilo que deu origem à ação. Mas ao mesmo tempo, entre o que ocorrer e o motivo (causa) dessa ação, temos a abertura 
para uma outra pergunta, que nos remete ao sentido mesmo da ação, ou seja, a pergunta pelo "quem" realizou tal ação. Nesse sentido, "a análise lógica das frases de ação, centrada no vínculo entre o quê e o como, não poderia obliterar a referência ao agente possuidor de sua ação" (RICOEUR, [2004] 2006, p. 113). Nesse ponto, a noção de adscrição evidencia a noção de atribuição de uma ação ao seu agente, dando um caráter de vinculação, ou melhor, de posse da ação. Assim, temos descrita "a capacidade de o próprio agente designar a si mesmo como aquele que faz ou fez [uma determinada ação]. Ela [a adscrição] faz a ligação do quê e do como ao quem" (RICOEUR, 2006, p. 113).

Talvez uma desconfiança com o "eu posso fazer", possa aparecer numa ação realizada coletivamente, isto é, em que medida seria possível, num nível grande de interações, definir qual parte da ação foi feita por cada um. Mas, como estamos no percurso do homem capaz, nos circunscrevemos no âmbito da ação ou parte da ação, em que o próprio sujeito se sente capaz de realizar, é nesse ato de tomar a iniciativa para si, que vemos desenvolver os movimentos interno-externo da pessoa no percurso do reconhecimento.

Para Ricoeur, um dos atos mais significativos da problemática em torno da identidade pessoal está no ato de narrar. O narrar-se lança a pessoa na condição de projetar a própria identidade pessoal na identidade narrativa, "em várias narrativas o si busca sua identidade na escala de uma vida inteira" (RICOEUR, 2014, p. 113).

Se, no primeiro momento, temos um homem que fala, no segundo, o homem que age, agora, já no terceiro, temos o homem capaz, lançado em um patamar de sua capacidade, que demonstra uma permanência: quer do $e l$, da relação, da duração, ao mesmo tempo que não exime que esse processo se dê na abertura à mudança e à ressignificação, pois "Aprender a 'narrar-se poderia ser o benefício [da] apropriação crítica. Aprender a narrar-se é também aprender a narrar a si mesmo de outro modo" (RICOEUR, 2006, p. 115).

\section{IDENTIDADE E IDENTIDADE NARRATIVA}

É nesse contexto que Ricoeur precisa lançar mão do termo identidade narrativa, uma vez que ao considerar que é possível narrar-se "de outro modo", ele assume uma problemática nova ou, de maneira nova, a problemática da identidade pessoal. Nesse sentido, o "si mesmo pode, assim, ser dito refigurado pela aplicação reflexiva das configurações narrativas. Ao contrário da identidade abstrata do Mesmo, a identidade narrativa, constitutiva da Ipseidade, pode incluir a mudança, a mutabilidade, na coesão de uma vida” (RICOEUR, 1994, p. 425). Mas, em que consiste objetivamente, nas nossas reflexões, a identidade? Qual a conexão da identidade narrativa para sustentação da própria noção de identidade? Assim nos responde Ricoeur em Tempo e narrativa, no enfrentamento dessa questão aporética:

O termo "identidade" é aqui tomado no sentido de uma categoria da prática. Dizer a identidade de um indivíduo ou de uma comunidade é responder à questão: Quem fez tal 
ação? Quem é o seu agente, o seu autor? Essa questão é primeiramente respondida nomeando-se alguém, isto é, designando-o por um nome próprio. Mas qual é o suporte da permanência do nome próprio? Que justifica que se considere o sujeito da ação, assim designado por seu nome, como o mesmo ao longo de toda uma vida, que se estende do nascimento à morte? A resposta só pode ser narrativa. Responder à questão “quem?", como dissera energicamente Hannah Arendt, é contar a história de uma vida (RICOEUR, [1983] 1994, p. 424).

O primeiro fator que nos remete ao fundamento metodológico adotado tanto na obra de Ricoeur, quanto em nossa abordagem, está no caráter diacrônico da compreensão, por isso, podemos falar que a identidade pessoal, entendida na duração, no tempo, pode ser definida como uma identidade narrativa e, com isso

a ideia de identidade narrativa dá acesso a uma nova abordagem do conceito de Ipseidade, que, sem a referência à identidade narrativa, é incapaz de desenvolver sua dialética específica, a da relação entre duas espécies de identidade, a identidade imutável do idem, do mesmo, e a identidade móvel do ipse, do si, considerada em sua condição histórica. É no quadro da teoria da narrativa que a dialética concreta da Mesmidade e da Ipseidade atinge um primeiro desenvolvimento, esperando por sua culminação com a teoria da promessa (RICOEUR, 2006, p. 116).

A identidade idem, mesmo estando associada à ideia de uma coisa que é considerada a mesma, mesmo na diversidade dos acontecimentos, não é eliminada pela identidade narrativa, mas toma-a em relação com a identidade ipse. Assim, os traços de permanência no tempo (com todas as dúvidas e hesitações) que vão "desde identidade biológica assinada pelo código genético, balizada pelas impressões digitais, a que se acrescentam a fisionomia, a voz, o jeito, passando pelos hábitos estáveis até as marcas acidentais por meio das quais um indivíduo se faz reconhecer" (RICOEUR, 2006, p. 116-117) estão, na identidade narrativa, em relação dialética com a identidade-ipse.

Ricoeur acredita que a problemática da identificação de si mesmo pode tornar-se tão confusa, até mesmo indecifrável que, no limite, podemos nos deparar com a pergunta: quem sou? Nesse ponto, estamos lançados numa dinamicidade da identidade-ipse que está sustentada na identidade ética, na medida que é mantida, pelo sujeito, a capacidade de prometer: "Como, com efeito, um sujeito de ação poderia dar à sua própria vida uma qualificação ética se essa vida não pudesse ser reunida na forma de narrativa?" (RICOEUR, 2006, p. 117). As incertezas, as obscuridades da existência e as próprias vicissitudes, na duração, da vida estão sempre e de novo em busca de uma configuração narrativa. Daí a promessa, em sua dialética com a memória, de "conduzir o destino da ipseidade, em desafio às circunstâncias que ameaçam arruinar a identidade do mesmo; a orgulhosa divisa 'eu manterei' carrega para a linguagem a manutenção arriscada da Ipseidade, enquanto manutenção de si fora da segurança da mesmidade" (RICOEUR, 2006, p. 117).

Se a discussão, apoiada na dialética identidade-idem e identidade-ipse mantem a relação de maneira privada, no âmbito da intimidade da subjetividade, quando colocamos em movimento a relação identidade narrativa e a dialética identidade-alteridade, já estamos no espaço de uma discussão pública "Uma história de vida 
se mistura à história da vida dos outros" (RICOEUR, 2006, p. 118). Há uma espécie de entrelaçamento originário entre as vidas das pessoas, uma mistura que, muitas vezes, seria impossível distinguir efetivamente esses momentos da relação. Podemos pensar, desde a fecundação em que estão envolvidos dois e depois três pessoas, passando pelas fases iniciais da vida, na ampliação do círculo inicial dos "cuidadores" até os outros envolvimentos que se dão ao longo da vida até a própria morte.

\section{MEMÓRIA E IDENTIDADE NARRATIVA}

Esse entrelaçamento, esse embaralhamento das vidas acontece não só no nível individual, entre pessoas de uma mesma comunidade ou grupo, mas, também entre os próprios grupos. Isso nos remete também à questão da memória em sua problemática: individual e coletiva: "Se se admite, como proponho, atribuir a capacidade de fazer memória a todos os sujeitos que encontram sua expressão lexical no uno (sic) qualquer dos pronomes pessoais, toda coletividade é qualificada para dizer 'nós outros', por ocasião de operações particulares de rememoração" (RICOEUR, 2006, p. 118). Assim, esse entrelaçamento das identidades narrativas, tanto de indivíduos quanto de grupos, também revela fragilidades que não nos deixam, por um lado, acreditar que haja uma forma totalizadora de definir o eu ou o nóse, ao mesmo tempo, nos ajuda a perceber que há uma necessidade de atenção para os usos e abusos dessas mesmas narrativas:

É na prova da confrontação com outrem, quer se trate de um indivíduo ou de uma coletividade, que a identidade narrativa revela sua fragilidade. As ameaças que atestam a fragilidade da identidade pessoal ou coletiva não são ilusórias: é digno de nota que as ideologias do poder procurem, com um sucesso inquietador, manipular essas identidades frágeis pelo viés das mediações simbólicas da ação, e principalmente graças a recursos de variação oferecidos pelo trabalho de configuração narrativa, pois é sempre possível, como dissemos anteriormente, narrar de um modo diferente. Esses recursos de reconfiguração tornam-se assim recursos de manipulação. A tentação identitária, que consiste no recuo da identidade-ipse em relação à identidade-idem, prospera nesse solo minado (RICOEUR, [2004] 2006, p. 118)

Por tanto, as vantagens da compreensão da identidade narrativa, tal como analisamos no pensamento de Ricoeur, não pode nos tirar a disposição constante de problematização das próprias narrativas, quer pessoais, quer coletivas, visto que a "ideia de uma compreensão de si e do mundo passa necessariamente [...] pela análise dos signos e das obras que encontramos no mundo e que precedem nossa existência individual" (GAGNEBIN, 1997, p. 266). Por outro lado, não podemos esquecer que é a confrontação da identidade narrativa e suas dialéticas individual (ipse-idem) e coletiva que possibilitam jogar um pouco de luz tanto na compreensão do eu quanto do outro e nessa relação de embaralhamento que consideramos, em linguagem ricoeuriana, originário do eu, com os próximos e os outros.

Após esse percurso, tendo em vista a questão dos riscos da manipulação narrativa tanto do eu quanto dos grupos, nos deparamos finalmente com uma questão que leva o homem capaz à sua realidade ética, isto é, 
chegamos à questão da imputalibidade. Somente o homem capaz, ou seja, aquele que fala, age e narra é capaz de responsabilizar-se, de reconhecer-se responsável por si, reconhecer-se capaz de falar, agir, narrar-se.

O reconhecimento leva o homem capaz, através da memória, a constatação de que posso ou podemos assumir a responsabilidade existencial pelos atos que realizou/realizamos e, através da promessa, que poderá realizar no futuro a palavra empenhada.

A imputabilidade é fruto de um processo cultural que estabelece a relação entre o "tornar o sujeito responsável por seus atos, a ponto de poder imputá-los a si mesmo" e o "poder assumir as consequências de seus atos, particularmente aqueles que são considerados um dano, um erro, do qual um outro é considerado vítima" (RICOEUR, 2006, p. 119). Nesse sentido, a concepção de reconhecimento que chega à imputabilidade ultrapassou a noção básica de "sujeito de direito". O reconhecimento da culpabilidade (individual ou coletiva) já nos coloca numa dimensão que está ligada aos predicados ético-morais: "com a imputabilidade, a noção de sujeito capaz atinge sua mais elevada significação, e a forma de autodesignação que ela implica inclui a de algum modo recapitula as formas precedentes de sui-référence”" (RICOEUR, 2006, p. 120).

Se a imputabilidade, quando tratada do ponto de vista jurídico, está relacionada com à ideia de reparação de uma injustiça ou com reparar os danos e infringir uma pena para o "quem" da ação delituosa, dentro de nossa perspectiva, a problemática está relacionada com uma autoprestação de contas. Com o estabelecimento pessoal ou coletivo de uma narrativa que sirva também para realizar um balanço das ações (ou omissões) realizadas. Por isso, o que mais nos interessa não é somente a imputação ou autoimputação de uma ação, que daria a impressão apenas de encontrar o sujeito da ação a qual é atribuída, mas o que realmente tem significado para nós é a noção de responsabilidade (apesar das controvérsias que existem nessa discussão), uma vez que ao compreendermos como o resultado de um percurso, no homem capaz, em que há apropriação ético-moral da ação, retirando assim, o caráter mais evidentemente jurídico da imputabilidade, mas não podemos perder de vista que

A faculdade narrativa é uma forma de percorrer o distanciamento, sem, contudo permitir-lhe que seja superado por completo o aspecto irreparável e imprevisível do tempo. Se a narrativa nos ensina a aceitar a incerteza, a decisão judicial deve também considerar que os seres no passado possuíam elementos irreparáveis e imprevisíveis (AMORIM, 2010, p. 23).

No entanto, se a ideia de responsabilidade implica não somente a atribuição de uma ação, a qual pode ser imputada também uma "pena", ela, por gerar poder, está sempre regulamentada pela noção de que toda ação (ou omissão) é imputável a alguém

[...] uma responsabilidade ilimitada geraria indiferença, ao arruinar o caráter "meu" de minha ação. Entre a fuga à responsabilidade e suas consequências e a inflação de uma responsabilidade infinita, é preciso encontrar a justa medida e não deixar o princípioresponsabilidade derivar para longe do conceito inicial de imputabilidade e de sua obrigação de reparar ou de sofrer a pena, nos limites de uma relação de proximidade local e temporal entre as circunstâncias da ação e seus eventuais efeitos danosos (RICOEUR, 2006, p. 122).

Se a responsabilidade amplia a noção de atribuição da ação, a imputabilidade não nos deixa esquecer que 
toda ação tem consequência que nos são incontornáveis.

O percurso do reconhecimento, que nos leva ao homem capaz, descortina, mais uma vez, a importância da memória. Sem a faculdade da memória, dificilmente, seríamos capazes de falar, agir e, especialmente, narrar a nossa vida (ou da comunidade). Além disso, sem a capacidade de lembrar e recordar, não teríamos como responsabilizar-nos, não perdendo de vista que a memória, como essas outras capacidades do homem capaz, também depende "desse modo de certeza que merece o nome de atestação, simultaneamente irrefutável em termos de prova cognitiva e submetida à suspeita, em virtude de seu caráter de crença”" (RICOEUR, 2010, p. 403).

Entretanto o mais significativo para nós, é que sem a memória, o processo do reconhecimento de si e mútuo também teria muitas dificuldades de ir a bom termo. Tanto é assim que, após essa exposição sobre o reconhecimento de si e suas bifurcações, passaremos agora para uma nova etapa ainda mais efetiva da relação memória e reconhecimento, ou seja, adentraremos efetivamente à discussão da dialética memória-promessa: "A problemática do reconhecimento de si atinge simultaneamente dois pontos culminantes com a memória e a promessa. Uma se volta para o passado, a outra para o futuro. Mas elas têm de ser pensadas conjuntamente no presente vivo do reconhecimento de si” (RICOEUR, 2006, p. 123).

No entanto, não podemos perder de vista uma constatação "natural". O percurso que nos conduz a uma maior compreensão do homem capaz, também nos revela que mesmo a capacidade desse homem está atrelada a uma incapacidade. Se é dada por uma recusa ou uma interdição, ainda assim, há momentos em que não é possível exercer a capacidade de falar, de agir, de narrar-se ou mesmo de lembrar. Tanto é assim que, até mesmo a memória, possui internamente uma capacidade e uma incapacidade que, mais que a descaracteriza, a plenifica:

A memória é internamente capacidade e incapacidade, vive da polaridade que tem juntado momentos que parecem se excluir (memória-hábito pura e repetições irrefletidas e a memória da lembrança que requer ação). Onde a capacidade poderia não funcionar, faltariam os aspectos de contraste. Por um lado, a memória pode alcançar efeitos surpreendentes através de técnicas refinadas, mas estéreis em termos da mnemotécnica, outro uso de memória pode tornar-se abusivo em termos de impedimento, manipulação e controle. Na sinergia entre o sujeito privilegiado da fenomenologia, e a coletividade promovida pela sociologia, si entrelaçam atividade e passividade mútua ${ }^{2}$ (AIME, 2007, p. $521)$.

O universo ricoeuriano compreende que há uma fissura, tanto no humano, quanto naquilo que nos constitui, por isso, não há o encontro de certezas definitivas e nem mesmo a superação da ferida que constitui o cogito, ou como ele mesmo denomina, somos, ao contrário do que Descartes pareceu encontrar, um Cogito

\footnotetext{
${ }^{2}$ La memoria è al próprio interno capacità e incapacita, vive della polarità che tiene insieme momenti che sembrano reciprocamente escludersi (la memoria-abitudine, pura e irriflessa repetizione, e la memoria-ricordo che richiede azione). Là dove la capacità può davvero esplicarsi non mancano gli aspetti di contrasto. Da un lato la memoria può raggiungere attraverso tecniche raffinate effetti sorprendenti ma isterilirsi in mnemotécnica, dall'altro l'uso della memoria può diventare abuso in termini di impedimento, manipolazione, comando. Nella sinergia tra il soggetto, privilegiato della fenomenologia, e la collettività, promossa dalla sociologia, si intrecciano attività e passività reciproche (AIME, 2007, p. 521).
} 
ferido. Tanto o homem capaz quanto a memória, ao pôr-se (ou serem postos), acabam revelando, as suas incapacidades e, portanto, a sua condição não é um dado pronto e acabado, mas, uma tarefa que se dá através de mediações, de relações entre o eue o mundo, entre o eue o outro, no percurso do reconhecimento.

\section{DIALÉTICA MEMÓRIA-PROMESSA}

A dialética memória-promessa está diretamente ligada às capacidades do homem capaz, isto é, se a memória é uma capacidade já vista por nós, justificando, portanto, a afirmação: "eu me lembro, eu posso me lembrar"; o prometer se inscreve nesse mesmo campo de possibilidade, no entanto, se a memória está relacionada ao passado, a promessa está no futuro, daí a afirmação "eu prometo, eu posso prometer" constituir uma espécie de ode à esperança baseada na capacidade de desafiar o que há de vir.

Curiosamente, essas duas capacidades, memória e promessa, só se realizam no presente vivo, na presentificação. Só nos lembramos no presente e só podemos prometer no agora da promessa.

Do ponto de vista do reconhecimento e da identidade pessoal, essa dialética memória-promessa tem uma configuração interessante, algo como uma espécie de prolongamento da dialética mesmidade-ipseidade, quer dizer, na memória, a ênfase estaria posta na Mesmidade (sem perder totalmente seu lastro com a Ipseidade, como vimos anteriormente) e a promessa teria seu relevo na Ipseidade, "a promessa é facilmente evocada como paradigma da ipseidade" (RICOEUR, 2006, p. 124).

Desse modo, ao tratar das capacidades anteriores do homem capaz, Ricoeur não apresentou o seu "lado negativo", a sua ameaça. No caso da memória e da promessa tratadas nessa relação dialética dentro do processo do reconhecimento, não será possível continuar sem ter presente a constante possiblidade de que as mesmas possam vir a "trair" a sua intenção originária; "[...] ambas têm relação com a ameaça de um negativo constitutivo do conteúdo de sentido: o esquecimento para a memória, a traição para a promessa. [...] seu contrário faz parte de seu sentido: lembrar-se é não esquecer; cumprir uma promessa é não traí-la” (RICOEUR, 2006, p. 124). Neste ponto de nossa discussão, teremos essa sombra do negativo como um pano de fundo de nossas análises.

Chama-nos a atenção que é através da discussão sobre a memória que o termo reconhecimento ganha novamente dignidade filosófica, uma vez que na pergunta ao "quem se lembra?" está contida a ideia mesma de que há um percurso do reconhecimento que se dá na lembrança.

Dois paradoxos estão implicados nesse processo, que desenvolvemos aqui: por um lado, temos o presente e o passado numa relação constante e atualizante, ou seja, o presente em algum momento se torna passado ao mesmo tempo em que ele era presente, curiosamente, "o passado é contemporâneo' do presente que ele foi", compreendemos, portanto, que no presente o passado é gerado, por isso, há uma certa inconsciência das lembranças que conservamos e veem a nós do passado e aqui entramos no outro paradoxo, isto é, esse 
movimento que acontece entre passado e presente e que nos coloca na busca desse passado acaba por gerar uma procura desse passado (sempre no presente) e, no caso da memória, "procurar é encontrar, e reencontrar é reconhecer o que se aprendeu anteriormente" (RICOEUR, 2006, p. 138). Podemos notar aqui uma questão fundamental, em alguma medida, a memória conserva a si mesma e essa "autoconservação é a própria duração" (RICOEUR, 2006, p. 138).

Essa passagem entre o passado e o futuro através do presente está evidente na dialética memóriapromessa, uma vez que a memória é retrospectiva e a promessa prospectiva. Assim, as duas, ao mesmo tempo em que são opostas, são também complementares quando pensando o reconhecimento, já que elas possibilitam uma amplitude temporal (devido à duração) no reconhecimento de si que é "fundado ao mesmo tempo em uma história da vida e em compromissos de futuro de longa duração" (RICOEUR, [2004] 2006, p. 138-139).

Essa dialética nos coloca novamente na dimensão de compreender o tempo em um aspecto que faz Ricoeur retomar o pensamento de Agostinho: "É o aspecto reencontrado da concepção agostiniana do tempo, cuja distensão provém da divergência íntima no presente, dividido entre o presente do passado ou memória, o presente do futuro ou expectação, e o presente do presente" (RICOEUR, 2006, p. 139).

O filósofo francês apresenta uma distinção em relação ao filósofo medieval, na medida em que a filosofia desse último estava quase que inteiramente dada no destaque à interiorização, à presença, Ricoeur pretende tirar da relação temporal e sua dialética memória-promessa não somente o aspecto de presença da memória, mas sua possibilidade de iniciativa, "ao contrário de Agostinho, será colocado por mim, em conformidade com uma filosofia do agir, sob o signo da iniciativa em vez de sob o signo da presença” (RICOEUR, [2004] 2006, p. 139). Aqui, podemos entender mais claramente a importância da dialética memória-promessa no pensamento de Ricoeur, ou seja, através dessa vicissitude é possível compreender e justificar como o reconhecimento também é uma abertura para o outro, além disso, perceber que o embaralhamento que se dá entre o eu e o outro também tem seu aporte no próprio embaralhamento do tempo (passado, presente e futuro), em nós e isso, certamente, implica em considerações que estão relacionadas com a questão da imputabilidade e da identidade narrativa.

No percurso do reconhecimento, tendo em vista uma identidade narrativa que colocou em movimento, em processo dialético a mesmidade-ipseidade, a promessa (por seu caráter mais afeito à ipseidade) se "vinculará à identidade narrativa, na qual essa dialética encontrou sua primeira expressão" (RICOEUR, 2006, p. 139). A narrativa põe em funcionamento a possiblidade dos deslocamentos temporais que vem do passado e chegam ao futuro, normalmente, como uma espécie de promessa. Por isso, essa última também possui a marca da alteridade, "ao contrário da memória, que é fortemente marcada pela "minhadade" que salienta seu caráter insubstituível. A relação com o outro é tão forte na promessa que esse traço poderá marcar a transição" entre a compreensão do reconhecimento de si e do mútuo, o que veremos abaixo. 
Talvez, alguém possa pensar que, mais que a memória, o que fundamenta a relação com o outro seja a promessa. Precisamos ter um pouco de cautela quando cogitamos a possibilidade de existir uma capacidade de promessa destituída de um fundamento na memória. A dialética que advogamos aqui não é a da superação, mas do movimento, muitas vezes, complementar entre os objetos da relação. À vista disso, prometer está alicerçado na capacidade, anteriormente demonstrada, do homem capaz e, somente isso, possibilita poder dizer, poder agir, poder narrar (uma promessa) e, mais, "formar a idéia da unidade narrativa de uma vida, por fim, poder imputar a si mesmo as origem dos próprios atos" (RICOEUR, [2004] 2006, p. 139-140). Ora, sem a memória essas outras capacidades dificilmente poderiam existir e co-existir. Por esse motivo, "é no ato por meio do qual o si se engaja efetivamente" (RICOEUR, [2004] 2006, p. 140) que podemos afirmar a capacidade da promessa e também da imputação.

A promessa possui duas frentes que estão divididas pela sua ordem temporal. A primeira é a dimensão discursiva do ato de prometer que gera o segundo momento: a característica moral, o cumprimento (ou não) do ato discursivo inicial.

Compreendendo a promessa como um ato ilocutório, contendo um enunciado declarativo, há uma força, no momento da enunciação, que traz um conjunto de verbos facilmente reconhecíveis no léxico: "quando diz 'eu prometo', o locutor é efetivamente 'engajado' em uma ação futura. Prometer é ser efetivamente engajado em 'fazer' o que a proposição enuncia” (RICOEUR, 2006, p. 140). Ao enunciar uma promessa, o locutor realiza um duplo movimento, ou melhor, cria uma dupla responsabilidade. A primeira, consigo mesmo, consiste em realizar aquilo que promete e, em seguida, com o beneficiário da ação prometida. Esse segundo momento, faz com que a promessa, normalmente, "não [tenha] somente um destinatário mas também um beneficiário" (RICOEUR, 2006, p. 140). Daí as palavras do enunciado da promessa ganharem um sentido moral, uma vez que geram uma expectação de um feito a ser realizado (no futuro). Ricoeur destaca a sua compreensão do que seja a promessa, portanto, "aquilo em que o locutor se engaja é fazer ou dar, não experimentar emoções, paixões ou sentimentos" (RICOEUR, 2006, p. 140). Tendo isso em vista, prometer é fazer ou dar e isso implica sempre uma responsabilidade com um outro (ou outros), além da responsabilidade consigo mesmo

A referência moral é suscitada pela própria idéia de força implicada na análise precedente: de onde o enunciador de uma promessa pontual retira sua força de poder se engajar? De uma promessa mais fundamental, a de manter a palavra em todas as circunstâncias; pode-se falar aqui da "promessa anterior à promessa". É justamente ela que dá a cada promessa seu caráter de engajamento: engajamento em relação a... e engajamento em... E é a esse engajamento que está ligado o caráter de ipseidade da promessa (RICOEUR, 2006, p. 141).

Essa ipseidade da promessa está ligada a uma vontade constante e não a um engessamento do desejo, aqui "fala" o coração do homem capaz de prometer, capaz de ser amigo

ao contrário da mesmidade típica da identidade biológica e de caráter do indivíduo, [essa ipseidade] consiste em uma vontade de constância, de manutenção de si, que coloca sua 
chancela sobre uma história de vida confrontada à alteração das circunstâncias e às vicissitudes do coração. É uma identidade mantida apesar de..., a despeito de..., de tudo o que inclinaria a trair sua palavra. Essa manutenção escapa ao traço desagradável da obstinação, quando assume a forma de uma disposição habitual, modesta e silenciosa em relação à palavra dada. É o que na amizade se chama de fidelidade (RICOEUR, [2004] 2006, p. 141).

A promessa tanto quanto a memória, apesar de suas constantes e recorrentes possiblidades de traições, possui confiabilidade, uma vez que as perfídias não superaram a credibilidade da mesma, pois "é da confiabilidade habitual ligada à promessa anterior à promessa que cada promessa pontual extrai sua credibilidade em face do beneficiário e da testemunha da promessa" (RICOEUR, 2006, p. 141). E o elemento declarativo, do ato inicial, tem como verificação a efetiva execução da promessa, desta forma, a promessa nunca é intangível.

Em paralelo à promessa, Ricoeur desenvolve uma interessante reflexão sobre o testemunho (que não constitui, no momento, um ponto que consideramos desenvolver mais longamente). O filósofo francês compara o ato ilocutório de prometer, ao testemunho, na medida em que o primeiro - promete - o futuro e o segundo garante - o passado. Ambos possuem uma tênue relação com a confiabilidade, a qual está posta numa espécie de aposta:

Surge então uma pergunta: até que ponto o testemunho é confiável? É aqui que entra em cena a confiabilidade ordinária da testemunha enquanto homem de promessa, à espera da confirmação ou infirmação que surge da confrontação de um testemunho com outro. Como a promessa não se baseia em um elemento declarativo, ela tem como teste unicamente sua execução efetiva: a manutenção ou não da palavra dada. Embora diferente em sua estrutura, o testemunho eventualmente recorre à promessa caso se peça à testemunha que renove seu depoimento. Desse modo, a testemunha é alguém que promete testemunhar novamente (RICOEUR, 2006, p. 142).

Por isso nos parece importante pensar o percurso do reconhecimento e a discussão da imputabilidade em relação, tanto é assim que, do ponto de vista das próprias decisões judiciais, o testemunho (sempre baseado na memória e na narrativa da testemunha) é um fator considerável:

Além disso, a associação entre narrativa e decisão do magistrado (ou da Corte) evidencia também o caráter prospectivo do conteúdo judicial. Na medida em que o olhar retrospectivo da decisão judicial é uma narrativa dos testemunhos, levando em conta elementos irreparáveis e imprevisíveis, de igual forma essa decisão deve considerar o imprevisível como algo que remete à incerteza quanto ao futuro. Nesse sentido, o esforço de interpretação implica em integrar o imprevisível de forma coerente com as decisões anteriores. Enisso reside o caráter prospectivo da decisão judicial (AMORIM, 2010, p. 24).

\section{CONSIDERAÇÕES FINAIS}

Abordamos, primeiramente, o reconhecimento de si e sua conexão com a ideia do homem capaz no pensamento de Ricoeur. As capacidades de falar, agir, narrar-se, ser responsável (imputável) e lembrar-se são fundamentais para entender o percurso que leva do existir ao reconhecer a si mesmo (sempre entendendo que é um percurso e não um fim, não há esgotamento do mistério do si para o si mesmo), do agir ao ser imputável 
(imputar-se). Ao mesmo tempo em que o homem pode realizar essas capacidades, uma outra ganha destaque, a capacidade de prometer que, junto à capacidade de lembrar, propicia a dialética memória-promessa, que constitui tanto uma afirmação do próprio quanto uma abertura ao outro.

Com uma perspectiva prática do que se entende por identidade, Ricoeur propõe pensar essa questão na ação, no que se constitui a afirmação do "quem" do sujeito da ação. Por isso o entendimento da identidade como uma narrativa, uma autonarrativa que dá conta de perceber a ipseidade dentro da duração, sem perder de vista a fissura que consiste em algo incontornável do humano. O homem capaz pode lembrar e pode prometer, duas capacidades que se relacionam com o passado e com o futuro, nesse entre que constitui o presente vivo. A promessa destaca ainda mais a relação com o outro, uma vez que a promessa sempre é feita a um outro que, normalmente, é o seu beneficiário. Logo, a dialética memória-promessa nos faz "atravessar" os umbrais do si mesmo em direção à alteridade, do reconhecimento de si ao mútuo.

A dialética memória-promessa em sua articulação com a questão da identidade narrativa nos possibilita compreender a problemática da imputabilidade e da responsabilidade como um caminho que passa por questões relativas à discussão sobre a subjetividade e a alteridade e, nesse sentido, o pensamento jus filosófico de Ricoeur nos permite refletir de modo novo e com um instrumental pouco viciado em como se dá o processo que nos leva do reconhecimento de si à imputação, do pertencimento ao grupo à responsabilidade.

Nesse sentido, podemos refletir sobre a necessidade de uma problematização, no que diz respeito ao processo e ao próprio reconhecimento tanto da própria responsabilidade nos atos individuais quanto nas ações coletivas, naquilo que possa ser considerado positivo e, também, no que causar um dano pessoal ou social. Ao propormos, a partir do pensamento de Ricoeur, uma reflexão que discute sobre a imputabilidade, a partir das categorias de subjetividade e alteridade, acreditamos enriquecer esse debate que recorrentemente assalta as conversas cotidianas e midiáticas, quer através das discussões sobre maioridade penal, quer nos linchamentos comuns no Brasil, quer na sensação, muitas vezes generalizada, de impunidade que nos aflige a todos.

\section{ON RICOEUR'S NARRATIVE IDENTITY AND IMPUTABILITY}

\section{Abstract}

This article is a result of an ongoing research which deals with Ricoeur's concerns on the relation between narrative identity and imputability. The debate proposed by the French philosopher approaches other categories such as: (1) self-recognition, which discusses the path covered by man towards identity understood as the comprehension of subjectivity as narrative in duration; (2) capable man, that describes human capacities such as "be-able-to-speak", "be-able-to-act" and "be able to be responsibilized" among others; (3) and the dialectical opposition memory-promise that shows the relation between past/remembrance connected to the witness' role and the promise which can only be fulfilled by someone responsible. This analysis aims to understand how man 
can impute himself and be imputed in his actions and, therefore, be responsible from the ethical, legal perspective. The uncertainties, the existence's obscurities and the vicissitudes themselves during one's life period are always seeking one narrative configuration. Concerning subjectivity's intimacy, when narrative identity is presented, we already are in a public debate.

Keywords: Ethics; Memory; Responsibility; Self-Recognition; Subjectivity

\section{REFERENCIAS}

AIME, O. Senso e essere. La filosofia riflessiva di Ricoeur. Assisi: Cittadella Editrice, 2007.

AMORIM, R. S. Contribuições de Paul Ricoeur para a Filosofia do Direito: uma entrevista com Olivier Abel. CAPTURA CRÍPTICA: direito, política, atualidade. Florianópolis, n.3., v.1., jul./dez. 2010. Disponível em http://capturacriptica.ccj.ufsc.br/wp-content/uploads/captura_criptica_-_n3v1_completo.pdf acessado em 25 de agosto de 2016.

GAGNEBIN, J. M. Uma filosofia do cogito ferido: Paul Ricoeur. ESTUDOS AVANÇADOS 11 (30), 1997. Disponível em http://www.revistas.usp.br/eav/article/view/9006 acessado em 18 de janeiro de 2016.

PAULA, A. C. de. Fenomenologia, hermenêutica e o mal como símbolo na filosofia de Paul Ricoeur. In: FERREIRA, A. M. C. Verdade e interpretação. Salvador: Quarteto, 2013.

RICOEUR, P. Percurso do reconhecimento. São Paulo: Edições Loyola, 2006. Edição original: 2004 A memória, a história, o esquecimento. Campinas, SP: Editora da Unicamp, 2010. Edição original: 2000 O si-mesmo como outro. São Paulo: Editora WMF Martins Fontes, 2014. Edição original: 1990. Tempo e narrativa. São Paulo: Papirus,1994. Edição original: 1983.

ROSA, J. M. S. Destruição da fatalidade: para um uso crítico da memória. In.: Coimbra: Lusosofia, 2006. Disponível em http://www.lusosofia.net/textos/jose_rosa_para_um_uso_critico_da_memoria.pdf acessado em 28 de dezembro de 2015.

Trabalho enviado em 05 de junho de 2017.

Aceito em 09 de setembro de 2017. 